\title{
Bike Modification and Upgradation
}

\author{
Akash Bhagat ${ }^{1}$, Arunesh Kujur ${ }^{2}$, Amit Ekka ${ }^{3}$ \\ ${ }^{1,2,3}$ Mechanical Engineering Department, MATS School of Engineering \& IT, Gullu, Raipur, Chhattisgarh, India
}

\begin{abstract}
In the present scenario motorcycle become major need for travelling. The purpose of our project was determining the various new concepts of modelling and adding and removing features. We took old bike, wanted to customize it and going to focus on the performance side. Most of the part are taken from the old bike rest of the parts are designed and manufactured. It is not a commuter using purpose it is for street racing. We make a custom motorcycle firstly we have found raw material for frame designing in order to replace existing frame, and we are taken hub steering system for better handling and wide tyre of wheels for better gripping with road with advance anti-lock braking system. Then we have done different type of customization regarding our project.
\end{abstract}

Keywords: modeling, design, frame and handling

\section{Introduction}

The project was a customized looking bike little bit similar to sports bike. A dual-sport motorcycle is a type of street motorcycle that is designed for both on and off-road use. The terms all-road and dual-purpose are also used for this class of motorcycles. But it is not a commuter using purpose bike. Vehicle is a modified street-bike with a $150 \mathrm{cc}$ liquidcooled DTSI engine. It contains a duel suspension at the centre of the vehicle with parallel manner. The frame design is different from other vehicle. The idea was to build a Customize motorcycle. We've taken references from different customized bike. And further studied about engine, suspension and brakes.

About this project we stroke different ideas at different stages so we decided to build customize motorcycle by Deassembly, Designing, Assembly and Testing.

\section{Literature Survey}

\subsection{Article}

Chopper City's Street-Legal Bike By Loz Blain July 29, 2010It is possible to customize the normal bikes to this type of typical design and build.

\subsection{Article}

The Hub Steering System By Craig Davis (B.Sc , University Of Cincinnati) May 2012. This steering system is scaled up for a high speed motorcycle it becomes more practical as higher velocities are obtained.

\subsection{Article}

The Rotating Wheel Mechanism of the Custom Bike by Betsy Megas (B.S., Mechanical engineering and materials science), 18 Dec, 2012. This article tells that wheel mechanism continues to rotate without any vibration. It should be reduces the jerk. Mechanical translational conserving port associated with the periphery and the wider wheel base keep the rider at the centre of gravity to the ground.

\subsection{Article}

Vietnamese Rider Creates His Own Custom Bike, By Damon Lowney, July 11th 2013. He built his own custom bike with Suzuki engine in its garage, so why can't we? So we are came to this project idea by building of our own...

\subsection{Article}

Research \& Development on Custom Frame (Static Moto Designs), 2011. This type of design is structurally stronger than any of the competitor's designs, And easier to control the bike at high speed and from this frame it less load on other section of bike.

\section{Methodology / Procedure}

1) Design and Engineering Relationship

We will nominally approach each problem from a every point of view during the time of design and our approach leads to empirically weighing the cause and effect of each design decision against the project's technical and economic design targets. Following are:

\section{Engine:}

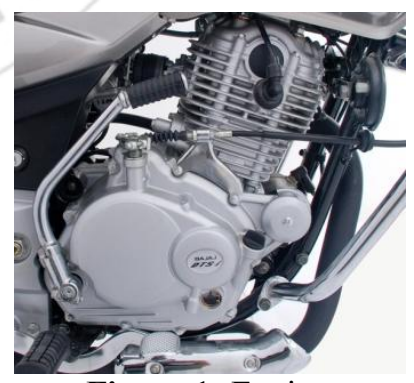

Figure 1: Engine

3.1 Four Stroke Engines, Working Principles, Applications - Types, Power and Efficiency

Heat engine is a machine for converting heat, developed by burning fuel into useful work. It can be said that heat engine is equipment which generates thermal energy and transforms it into mechanical energy. 


\section{International Journal of Science and Research (IJSR) \\ ISSN (Online): 2319-7064}

Index Copernicus Value (2013): 6.14 | Impact Factor (2014): 5.611

\subsubsection{Classification of Heat Engines \\ 1. External Combustion Engine. \\ 2. Internal Combustion Engine.}

\section{1) External Combustion Engine}

Here, the working medium, the steam, is generated in a boiler, located outside the engine and allowed in to the cylinder to operate the piston to do mechanical work.

\section{2) Internal Combustion Engine}

In internal combustion engine, the combustion of fuel takes place inside the engine cylinder and heat is generated within the cylinder. This heat is added to the air inside the cylinder and thus the pressure of the air is increased tremendously. This high pressure air moves the piston which rotates the crank shaft and thus mechanical work is done.

\subsection{Working Principle of I.C. Engine/ Four Stroke Cycle Engine}

A mixture of fuel with correct amount of air is exploded in an engine cylinder which is closed at one end. As a result of this explosion, heat is released and this heat causes the pressure of the burning gases to increase. This pressure forces a close fitting piston to move down the cylinder. The movement of piston is transmitted to a crankshaft by a connecting rod so that the crankshaft rotates and turns a flywheel connected to it. Power is taken from the rotating crank shaft to do mechanical work. To obtain continuous rotation of the crank shaft the explosion has to be repeated continuously.

Before the explosion to take place, the used gases are expelled from the cylinder, fresh charge of fuel and air are admitted in to the cylinder and the piston moved back to its starting position. The sequence of events taking place in an engine is called the working cycle of the engine. The sequences of events taking place inside the engine are as follows:

1) Admission of air or air-fuel mixture inside the engine cylinder (suction).

2) Compression of the air or air fuel mixture inside the engine (compression).

3) Injection of fuel in compressed air for ignition of the fuel or ignition of air-fuel mixture by an electric spark using a spark plug to produce thermal power inside the cylinder (power).

4) Removal of all the burnt gases from the cylinder to receive fresh charge (exhaust).

\subsection{Four Stroke Cycle Engine (Petrol Engine)}

In four stroke cycle engines the four events namely suction, compression, power and exhaust take place inside the engine cylinder. The four events are completed in four strokes of the piston (two revolutions of the crank shaft). This engine has got valves for controlling the inlet of charge and outlet of exhaust gases. The opening and closing of the valve is controlled by cams, fitted on camshaft. The camshaft is driven by crankshaft with the help of suitable gears or chains. The camshaft runs at half the speed of the crankshaft.
The events taking place in I.C. engine are as follows:

1) Suction stroke

2) Compression stroke

3) Power stroke

4) Exhaust stroke

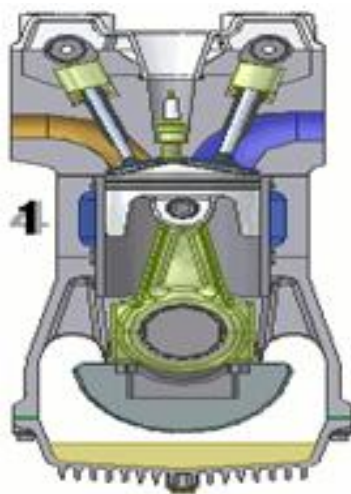

Figure 2: Four Stroke Cycle Engine

\subsubsection{Suction Stroke}

During suction stroke inlet valve opens and the piston moves downward. Only air or a mixture of air and fuel are drawn inside the cylinder. The exhaust valve remains in closed position during this stroke. The pressure in the engine cylinder is less than atmospheric pressure during this stroke.

\subsubsection{Compression Stroke}

During this stroke the piston moves upward. Both valves are in closed position. The charge taken in the cylinder is compressed by the upward movement of piston. If only air is compressed, as in case of diesel engine, diesel is injected at the end of the compression stroke and ignition of fuel takes place due to high pressure and temperature of the compressed air. If a mixture of air and fuel is compressed in the cylinder, as in case of petrol engine, the mixture is ignited by a spark plug.

\subsubsection{Power Stroke}

After ignition of fuel, tremendous amount of heat is generated, causing very high pressure in the cylinder which pushes the piston downward. The downward movement of the piston at this instant is called power stroke. The connecting rod transmits the power from piston to the crank shaft and crank shaft rotates. Mechanical work can be taped at the rotating crank shaft. Both valves remain closed during power stroke.

\subsubsection{Exhaust Stroke}

During this stroke piston moves upward. Exhaust valve opens and exhaust gases go out through exhaust valves opening. All the burnt gases go out of the engine and the cylinder becomes ready to receive the fresh charge. During this stroke inlet valve remains closed. Thus it is found that out of four strokes, there is only one power stroke and three idle strokes in four stroke cycle engine. The power stroke supplies necessary momentum for useful work.

\subsection{Engine Components}

Internal combustion engine consists of a number of parts which are given below: 


\section{International Journal of Science and Research (IJSR) \\ ISSN (Online): 2319-7064 \\ Index Copernicus Value (2013): 6.14 | Impact Factor (2014): 5.611}

1. CYLINDER: It is a part of the engine which confines the expanding gases and forms the combustion space. It is the basic part of the engine. It provides space in which piston operates to suck the air or air-fuel mixture. The piston compresses the charge and the gas is allowed to expand in the cylinder, transmitting power for useful work. Cylinders are usually made of high grade cast iron.

2. CYLINDER BLOCK: It is the solid casting body which includes the cylinder and water jackets (cooling fins in the air cooled engines).

3. CYLINDER HEAD: It is a detachable portion of an engine which covers the cylinder and includes the combustion chamber, spark plugs or injector and valves.

4. CYLINDER LINER OR SLEEVE: It is a cylindrical lining either wet or dry type which is inserted in the cylinder block in which the piston slides.

Liners are classified as :(1) Dry liner and (2) Wet liner.

Dry liner makes metal to metal contact with the cylinder block casing. wet liners come in contact with the cooling water, whereas dry liners do not come in contact with the cooling water.

5. PISTON: It is a cylindrical part closed at one end which maintains a close sliding fit in the engine cylinder. It is connected to the connecting rod by a piston pin. The force of the expanding gases against the closed end of the piston, forces the piston down in the cylinder. This causes the connecting rod to rotate the crankshaft. Cast iron is chosen due to its high compressive strength. Aluminum and its alloys preferred mainly due to it lightness.

6. PISTON RING: It is a split expansion ring, placed in the groove of the piston. They are usually made of cast iron or pressed steel alloy. The function of the ring are as follows :

- It forms a gas tight chamber for all positions of pistons

- It reduces contact area between cylinder wall and piston wall preventing friction losses and excessive wear.

- It controls the cylinder lubrication.

- It transmits the heat away from the piston to the cylinder walls.

- Piston rings are of two types:

$>$ Compression ring

$>$ Oil ring

\section{Compression Ring}

Compression rings are usually plain, single piece and are always placed in the grooves of the piston nearest to the piston head. They prevent leakage of gases from the cylinder and helps increasing compression pressure inside the cylinder.

\section{Oil Ring}

Oil rings are grooved or slotted and are located either in lowest groove above the piston pin or in a groove above the piston skirt. They control the distribution of lubrication oil in the cylinder and the piston.

\section{Piston Pin}

It is also called wrist pin or gudgeon pin. Piston pin is used to join the connecting rod to the piston.

7. CONNECTING ROD: It is special type of rod, one end of which is attached to the piston and the other end to the crankshaft. It transmits the power of combustion to the crankshaft and makes it rotate continuously. It is usually made of drop forged steel.

8. CRANKSHAFT: It is the main shaft of an engine which converts the reciprocating motion of the piston into rotary motion of the flywheel. Usually the crankshaft is made of drop forged steel or cast steel. The space that supports the crankshaft in the cylinder block is called main journal, whereas the part to which connecting rod is attached is known as crank journal. Crankshaft is provided with counter weights throughout its length to have counter balance of the unit.

8.1 FLYWHEEL: Flywheel is made of cast iron. Its main functions are as follows:

a. It stores energy during power stroke and returns back the energy during the idle strokes, providing a uniform rotary motion of flywheel.

b. The rear surface of the flywheel serves as one of the pressure surfaces for the clutch plate.

c. Engine timing marks are usually stamped on the flywheel, which helps in adjusting the timing of the engine.

a. Sometime the flywheel serves the purpose of a pulley for transmitting power.

9. CRANK CASE: The crankcase is that part of the engine which supports and encloses the crankshaft and camshaft. It provides a reservoir for the lubricating oil. It also serves as a mounting unit for such accessories as the oil pump, oil filter, starting motor and ignition components. The upper portion of the crankcase is usually integral with cylinder block. The lower part of the crankcase is commonly called oil pan and is usually made of cast iron or cast aluminum.

10. CAMSHAFT: It is a shaft which raises and lowers the inlet and exhaust valves at proper times. Camshaft is driven by crankshaft by means of gears, chains or sprockets. The speed of the camshaft is exactly half the speed of the crankshaft in four stroke engine. Camshaft operates the ignition timing mechanism, lubricating oil pump and fuel pump. It is mounted in the crankcase, parallel to the crankshaft.

11. TIMING GEAR: Timing gear is a combination of gears, one gear of which is mounted at one end of the camshaft and the other gear at the crankshaft. Camshaft gear is bigger in size than that of the crankshaft gear and it has twice as many teeth as that of the crankshaft gear. For this reason, this gear is commonly called half time gear. Timing gear controls the timing of ignition, timing of opening and closing 


\section{International Journal of Science and Research (IJSR) \\ ISSN (Online): 2319-7064}

Index Copernicus Value (2013): 6.14 | Impact Factor (2014): 5.611

of valve as well as fuel injection timing

12. INLET MANIFOLD: It is that part of the engine through which air or air-fuel mixture enters into the engine cylinder. It is fitted by the side of the cylinder head.

13. EXHAUST MANIFOLD: It is that part of the engine through which exhaust gases go out of the engine cylinder. It is capable of withstanding high temperature of burnt gases. It is fitted by the side of the cylinder head.

14. TOP DEAD CENTRE: When the piston is at the top of its stroke, it is said to be at the top dead centre (TDC),

15. BOTTOM DEAD CENTRE: When the piston is at the bottom of its stroke, it is said to be at its bottom dead centre(BDC).In two stroke cycle engine both the sides of the piston are effective which is not the case in four stroke cycle engine.

16. SCAVENGING: The process of removal of burnt or exhaust gases from the engine cylinder is known as scavenging. Entire burnt gases do not go out in normal stroke, hence some type of blower or compressor is used to remove the exhaust gases in two stroke cycle engine.

\subsection{Terminology Connected with Engine Power}

- Bore- Bore is the diameter of the engine cylinder.

- Stroke - It is the linear distance traveled by the piston from Top dead centre (TDC) to Bottom dead centre (BDC).

- Stroke-bore ratio -The ratio of length of stroke (L) and diameter of bore (D) of the cylinder is called stroke-bore ratio $(\mathrm{L} / \mathrm{D})$. In general, this ratio varies between 1 to 1.45 and for tractor engines, this ratio is about 1.25 .

- Swept volume - It is the volume (A x L) displaced by one stroke of the piston where A is the cross sectional area of piston and $\mathrm{L}$ is the length of stroke.

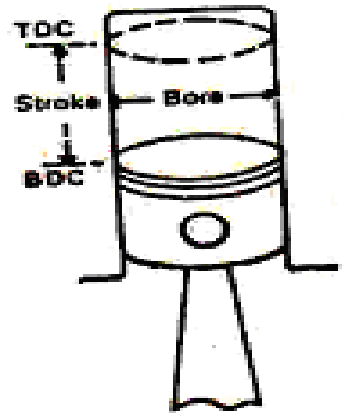

Figure 3: Bore and stroke of IC engine

Compression ratio - It is the ratio of the volume of the cylinder at the beginning of the compression stroke to that at the end of compression stroke, i.e. ratio of total cylinder volume to clearance volume.

The Compression ratio of diesel engine varies from 14:1 to $22: 1$ and that of carburetor type engine (spark ignition engine) varies from $4: 1$ to $8: 1$.

Power - It is the rate of doing work. S.I. unit of power is watt.

Watt $=$ Joule $/$ sec. $(4.2$ Joules $=1$ Calorie $)$.

In metric unit the power can be expressed in $\mathrm{kgm} / \mathrm{sec}$.

Horse power (HP)- It is the rate of doing work. Expressed in horse power Conversion factors from work to power 4500 $\mathrm{kgm}$ of work $/$ minute $=1.0 \mathrm{hp} 75 \mathrm{kgm}$ of work $/$ second $=$ $1.0 \mathrm{hp}$.

Indicated horse power (IHP) - It is the power generated in the engine cylinder and received by the piston. It is the power developed in a cylinder without accounting frictional losses.

$$
\begin{aligned}
& \mathrm{IHP}=\frac{\text { PLAN }}{4500} \quad \frac{\mathrm{n}}{2} \text { (for four stroke engine) } \\
& \mathrm{IHP}=\frac{\text { PLAN }}{4500} \quad \text { for two stroke engine) }
\end{aligned}
$$

Where, $\mathrm{P}=$ mean effective pressure $\left(\mathrm{kg} / \mathrm{cm}^{2}\right)$

$\mathrm{A}=$ cross-sectional area of piston $\left(\mathrm{cm}^{2}\right)$

$\mathrm{L}=$ stroke length $(\mathrm{m})$

$\mathrm{N}=$ engine revolution per minute

$\mathrm{n}=$ number if cylinder

In SI unit, indicated horse power is given as below:

Indicated Horse Power (IHP), $\mathrm{kW}=\frac{\text { PLAN }}{60} \quad 10^{12} \quad \frac{\mathrm{n}}{2}$

(for four stroke engine)

Indicated horse power (IHP), $\mathrm{kW}=\frac{\text { PLAN }}{6010^{12}}$

(for two stroke engine)

Where, $\mathrm{P}=$ mean effective pressure, $\mathrm{Pa}$ (Pascal)

$\mathrm{L}=$ length of stroke ( $\mathrm{mm})$

$\mathrm{A}=$ area of piston $(\mathrm{mm})$

$\mathrm{N}=$ speed $(\mathrm{rpm})$

Brake horse power (BHP) - It is the power delivered by the engine at the end of the crankshaft. It is measured by a dynamometer.

Where, $\mathrm{T}=$ Torque $(\mathrm{kgm})$

$$
\mathrm{BHP}=\frac{2 \pi \mathrm{NT}}{4500} \mathrm{hp}
$$

$\mathrm{N}=$ speed $(\mathrm{rpm})$

Belt horse power - It is the power of the engine measured at a pulley receiving drive from the PTO shaft of the tractor.

Power take-off horse power (PTO HP) - It is the power delivered by a tractor through its PTO shaft. In general, the belt and PTO horse power of a tractor will approximately be the same. The PTO hp is around $80-85 \%$ of tractor engine power

Drawbar horse power (DBHP) - It is the power of a tractor measured at the drawbar of a tractor. It is that power which is available for pulling loads. It is around $50-55 \%$ of engine power

Frictional horse power (FHP) - It is the power required to run the engine at a given speed without producing any useful 


\section{International Journal of Science and Research (IJSR) \\ ISSN (Online): 2319-7064}

Index Copernicus Value (2013): 6.14 | Impact Factor (2014): 5.611

work. It represents the friction and pumping losses of an engine.

$\mathrm{IHP}=\mathrm{BHP}+\mathrm{FHP}$

\section{Shock Absorber}

Pneumatic and hydraulic shock absorbers are used in conjunction with cushions and springs. An automobile shock absorber contains spring-loaded check valves and orifices to control the flow of oil through an internal piston (see below).

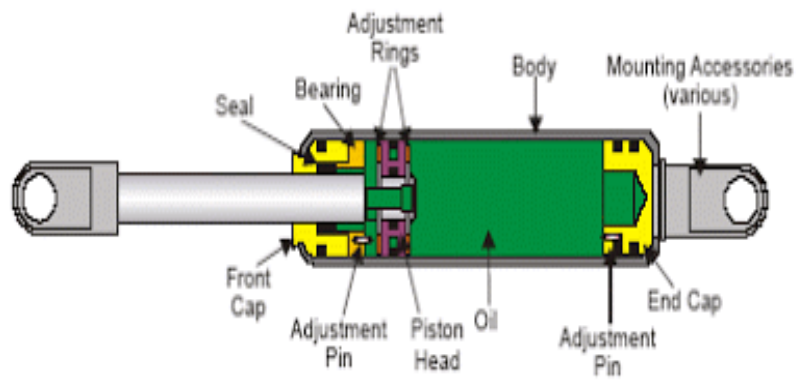

Figure 4: Shock absorber

One design consideration, when designing or choosing a shock absorber, is where that energy will go. In most shock absorbers, energy is converted to heat inside the viscous fluid. In hydraulic cylinders, the hydraulic fluid heats up, while in air cylinders, the hot air is usually exhausted to the atmosphere. In other types of shock absorbers, such as electromagnetic types, the dissipated energy can be stored and used later. In general terms, shock absorbers help cushion vehicles on uneven roads.

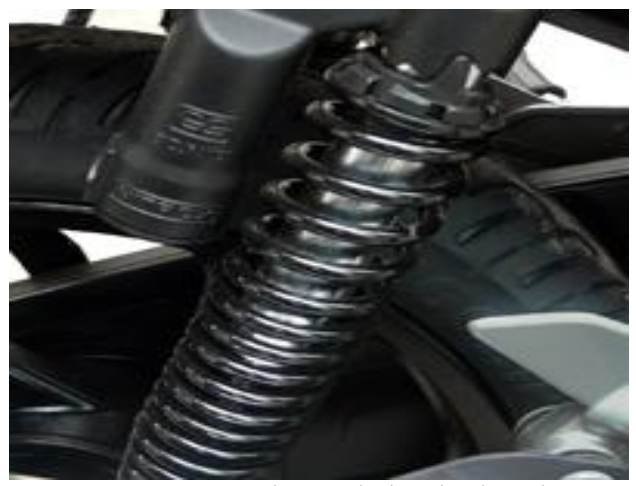

Figure 5: Gas charged shock absorber

The rear shock absorbers on current Bajaj Pulsar series bikes are also popularly known as NITROUS shock absorbers. These types of shock absorbers are actually called as _ans Filled Shock Absorbers'. The visual differentiation between a conventional shock absorber and a gas filled shock absorber is a small canister (box) which is attached on one side of it. This canister holds a small amount of Nitrogen gas in it. Hence these hydraulic shock absorbers or dampers are called as gas filled shock absorbers. So what is the reason to use a gas filled hydraulic dampers instead of using a conventional one? We'll find out the answer here.

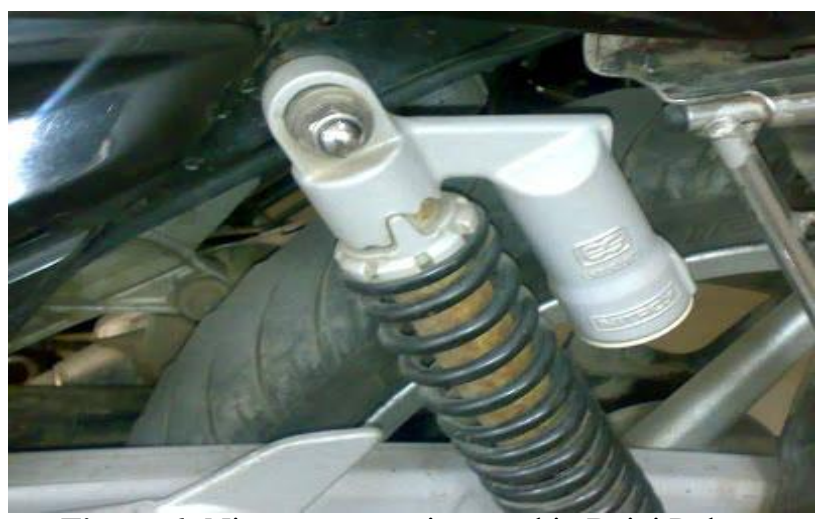

Figure 6: Nitrous suspension used in Bajaj Pulsar

A typical shock absorber or an hydraulic damper contains oil with two tubes sliding inside one another and also has a piston inside. It also has valves inside. The oil inside the damper moves along the valves as the piston moves up and down to absorb the shocks. These dampers have a tendency for the oil to form foam (form bubbles) under heavy use and riding conditions. The foaming is usually caused by air bubbles inside oil during suspension action. This is similar to shaking a can of oil. After shaking the oil inside the can gets foamed. Similarly the same case happens to a hydraulic damper also. This foaming temporarily reduces the damping ability of the unit.

In order to solve this, a secondary cylinder is connected to the shock absorber which acts as a reservoir for the oil and pressurized gas (nitrogen). The pressurized nitrogen gas inside the canister prevents foaming of hydraulic oil inside the damper.

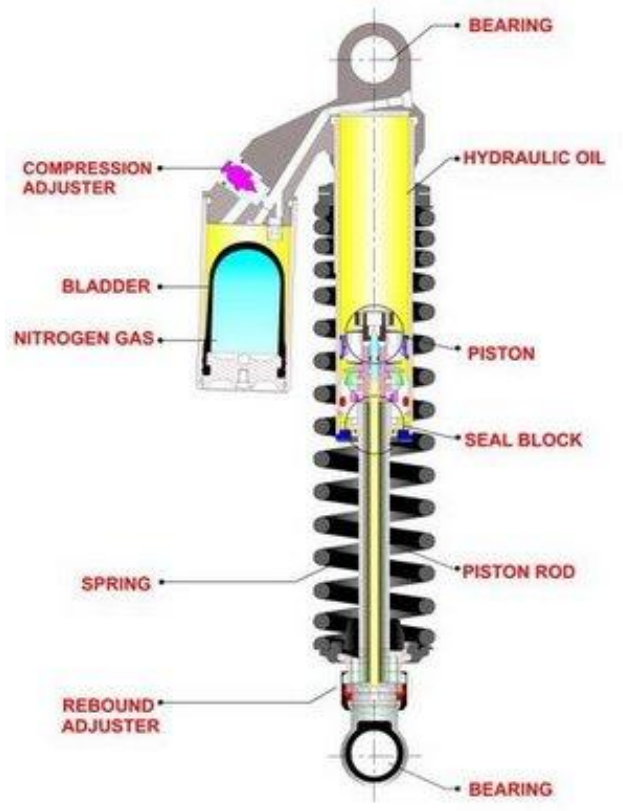

Figure 7: Cut section of Nitrous suspension

This nitrogen gas also helps in absorbing the road undulations and provides a smooth ride for both the rider and the pillion. The new Bajaj Pulsar 150cc uses a Nitrous piggy-back type canister gas filled suspension. It is a kind of gas filled suspension to be used in Indian bikes. These type of dampers provide better stability and also provides comfortable long rides to riders as the performance remains unchanged since the foaming never occurs.

\section{Volume 5 Issue 3, March 2016}




\section{International Journal of Science and Research (IJSR) \\ ISSN (Online): 2319-7064 \\ Index Copernicus Value (2013): 6.14 | Impact Factor (2014): 5.611}

\section{Wheels}

A wheel is a circular component that is intended to rotate on an axle bearing. The wheel is one of the main components of the wheel and axle which is one of the six simple machines. Wheels, in conjunction with axles, allow heavy objects to be moved easily facilitating movement or transportation while supporting a load, or performing labor in machines. Wheels are also used for other purposes, such as a ship's wheel, steering wheel, potter's wheel and flywheel.

A wheel greatly reduces friction by facilitating motion by rolling together with the use of axles. In order for wheels to rotate, a moment needs to be applied to the wheel about its axis, either by way of gravity, or by the application of another external force or torque.

\section{Tyre}

A tyre is a ring-shaped covering that fits around a wheel rim to protect it and enable better vehicle performance by providing a flexible cushion that absorbs shock while keeping the wheel in close contact with the ground. The word itself may be derived from the word "tie," which refers to the outer steel ring part of a wooden cart wheel that ties the wood segments together.

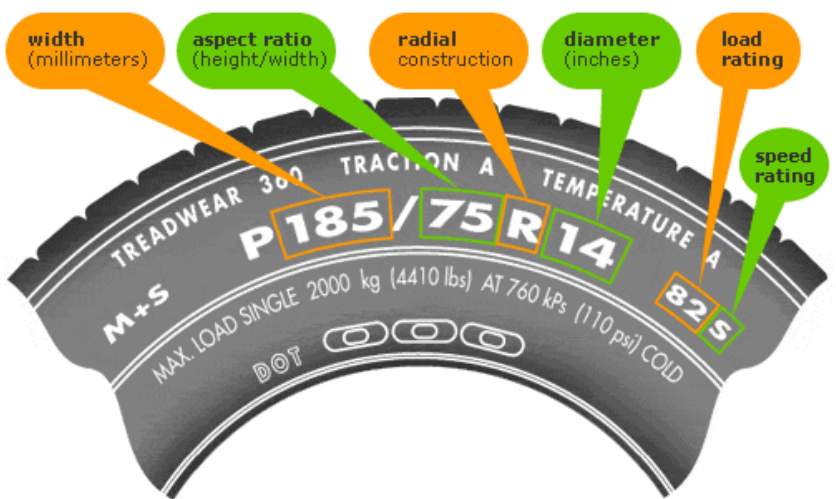

Figure 8: Tyre specification

The fundamental materials of modern tyre are synthetic rubber, natural rubber, fabric and wire, along with other compound chemicals. They consist of a tread and a body. The tread provides traction while the body ensures support. Before rubber was invented, the first versions of tyre were simply bands of metal that fitted around wooden wheels to prevent wear and tear. Today, the vast majorities of tyre are pneumatic in flatable structures, comprising a doughnutshaped body of cords and wires encased in rubber and generally filled with compressed air to form an inflatable cushion.

A wider tyre has a larger contact area with the road beneath our wheels, adding a modicum of extra traction - a welcome attribute in wet conditions - and making pinchflats less likely.

The performance of a wider tyre is less compromised by lower pressures, compared to a $23 \mathrm{~mm}$ tyre. But in a cycling world obsessed with aerodynamic advantages, surely wider is slower?

It's easier to accommodate wider tyres on wider rims, thus avoiding detrimental effects on aerodynamics. On a narrow,
$19 \mathrm{~mm}$ rim, a bigger-profile tyre balloons, causing more drag, so that any advantage gained from the decreased rolling resistance is void by the increased drag. A wider, $23 \mathrm{~mm}$ rim with a $25 \mathrm{~mm}$ tyre allows the rim and tyre to sit flush with each other, thus making airflow far smoother.

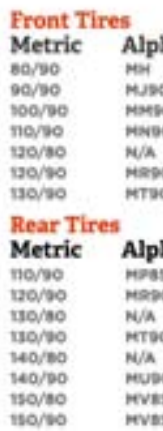

\begin{tabular}{|c|c|c|c|}
\hline & \multicolumn{3}{|c|}{ Front Tires } \\
\hline & Metric & Alpha & Inch \\
\hline $2.50 / 2.78$ & 60/า00 & $90 / 30$ & $2.50 / 2.7 \mathrm{~s}$ \\
\hline $2.7 / 2 \infty$ & xa/noo & $90 / 30$ & $2.73 / 100$ \\
\hline $3.25 / 3.50$ & so/noo & 100/so & $3.00 / 3.25$ \\
\hline $\begin{array}{l}3.75 / 400 \\
4.35 / 4.50\end{array}$ & Rear Tires & & \\
\hline $\begin{array}{l}1.25 / 4.50 \\
0\end{array}$ & Metric & Alpha & Inch \\
\hline $5.00 / 3.10$ & Ba/noo & 80/90 & $2.50 / 2.60$ \\
\hline & $20 / 700$ & no/2o & $3.60 / 4.10$ \\
\hline & $100 / 700$ & $120 / 80$ & $4.00 / 4.10$ \\
\hline Inch & no/10o & $130 / 90$ & $4.00 / 4.50$ \\
\hline 4.5o/4035 & $120 / 700$ & $140 / 60$ & $3.00 / 1.10$ \\
\hline 4.so/4.7s & & & \\
\hline $3.00 / 5.10$ & & & \\
\hline $800 / 3.10$ & & & \\
\hline $3.50 / 6.00$ & & & \\
\hline $3.50 / 600$ & & & \\
\hline $0.00 / 6.28$ & & & \\
\hline & & & \\
\hline
\end{tabular}

Figure 9: Tyre conversion chart

\section{- Research and Concept Design}

As the normal procedure of developing a new motorcycle involves the same steps in other professional design disciplines: identifying a target, researching them to identify benchmarks and project targets, and then propose the concept directions in a written form.

We select the old 2008 model Pulsar 150CC motorbike. We've selected this motorbike because it suitable to our project. It fulfils our requirement for the project and perfect for project design.

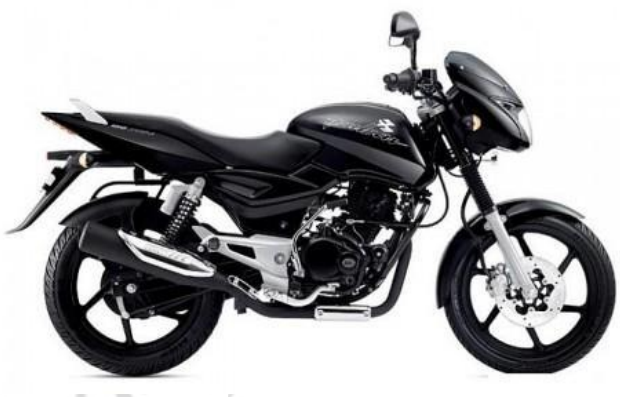

Figure 10: Bajaj Pulsar 150 CC

Finally a satisfactory design is established on paper then full scale modeling begins to realize the design in tangible $3 \mathrm{D}$ form.

\section{- Parallel Development}

Because of the need to reduce time and costs, the "styling" design model is usually developed in parallel with the engineering 3D design. While there is an increasing amount of digital design input in our design process and for analysis. We decided to use suitable 3D software packages SOLIDWORKS.

\section{D MODELLING SOLIDWORKS}

Solid Works is a solid modeler, and utilizes a parametric feature-based approach to create models and assemblies. The software is written on Para solid-kernel.

Parameters refer to constraints whose values determine the shape or geometry of the model or assembly. Parameters can be either numeric parameters, such as line lengths or circle diameters, or geometric parameters, such as tangent, 


\section{International Journal of Science and Research (IJSR) \\ ISSN (Online): 2319-7064 \\ Index Copernicus Value (2013): 6.14 | Impact Factor (2014): 5.611}

parallel, concentric, horizontal or vertical, etc. Numeric parameters can be associated with each other through the use of a relation, which allows them to capture design intent.

Design intent is how the creator of the part wants it to respond to changes and updates. For example, you would want the hole at the top of a beverage can to stay at the top surface, regardless of the height or size of the can. Solid Works allows the user to specify that the hole is a feature on the top surface, and will then honor their design intent no matter what height they later assign to the can.

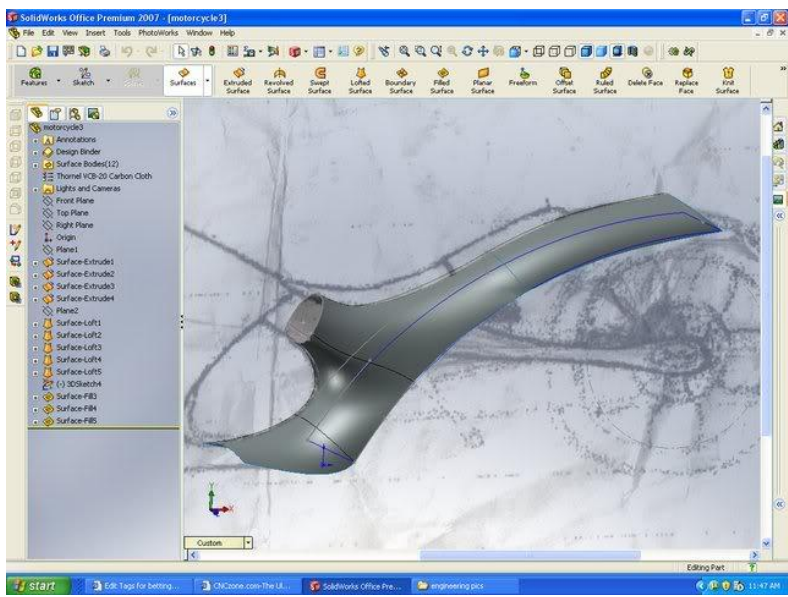

Figure 11: 3D modeling

Features refer to the building blocks of the part. They are the shapes and operations that construct the part. Shapebased features typically begin with a $2 \mathrm{D}$ or $3 \mathrm{D}$ sketch of shapes such as bosses, holes, slots, etc. This shape is then extruded or cut to add or remove material from the part. Operation-based features are not sketch-based, and include features such as fillets, chamfers, shells, applying draft to the faces of a part, etc.

Building a model in Solid Works usually starts with a 2D sketch (although 3D sketches are available for power users). The sketch consists of geometry such as points, lines, arcs, conics (except the hyperbola), and splines. Dimensions are added to the sketch to define the size and location of the geometry. Relations are used to define attributes such as tangency, parallelism, perpendicularity, and concentricity. The parametric nature of SolidWorks means that the dimensions and relations drive the geometry, not the other way around. The dimensions in the sketch can be controlled independently, or by relationships to other parameters inside or outside of the sketch.

In an assembly, the analog to sketch relations are mates. Just as sketch relations define conditions such as tangency, parallelism, and concentricity with respect to sketch geometry, assembly mates define equivalent relations with respect to the individual parts or components, allowing the easy construction of assemblies. SolidWorks also includes additional advanced mating features such as gear and cam follower mates, which allow modeled gear assemblies to accurately reproduce the rotational movement of an actual gear train.
Finally, drawings can be created either from parts or assemblies. Views are automatically generated from the solid model, and notes, dimensions and tolerances can then be easily added to the drawing as needed. The drawing module includes most paper sizes and standards (ANSI, ISO, DIN, GOST, JIS, BSI and SAC).

\section{- Style}

We often used as an interchangeable term with "design", styling is in fact just one component of the design process. Typically, our styling is developed through sketches, renderings and illustrations then realized in 3D form. Find motorcycle images that the style, lines, riding position etc appeals to we gather as many photo/drawings/images of motorcycles that we like the look of as a complete bike. Include any imagery that we feel we want to include or take inspiration from which we can use to integrate within the design. As the most subjective part of the design process, the members of the team give ideas suggested methods and finally the judgment to create an appropriate look.

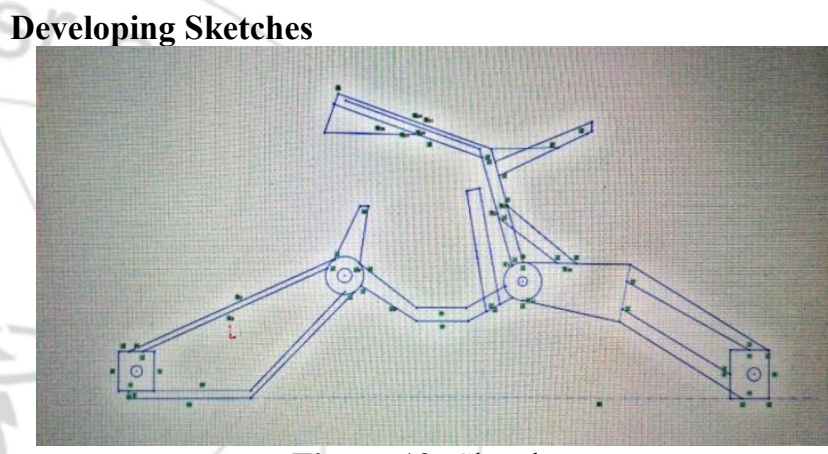

Figure 12: Sketches

\section{Step 1-Disassembly}

The disasssembly is uninstalling the parts of the motorbike from which get the following useful part that we were used in our project. We were taken out the mainly the engine, rear shock absorber, disc brake and other electrical parts.

\section{Step 2 - Design}

2.1 Motorcycle Frame Geometry Made Simple: How your motorcycle handles.

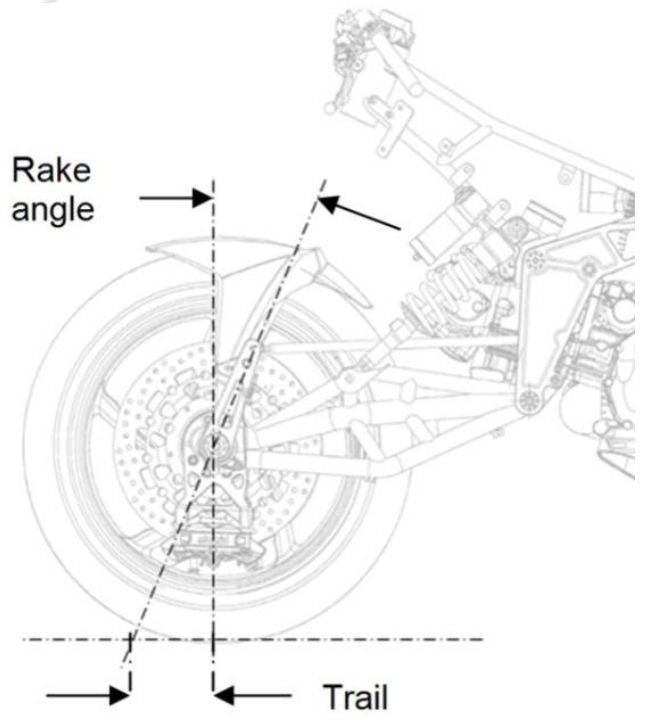

Figure 13: Frame Geometry

\section{Volume 5 Issue 3, March 2016}




\section{International Journal of Science and Research (IJSR) \\ ISSN (Online): 2319-7064 \\ Index Copernicus Value (2013): 6.14 | Impact Factor (2014): 5.611}

Frame geometry, rake and trail are important components in how your motorcycle rides, but that doesn't make them any less complicated or frustrating to understand. So today we're going to simplify it for you and show you how rake and trail work hand-in-hand to enhance your motorcycle's performance.

Let's start by defining rake and trail:

Rake is the angle of the steering head - measured in degrees - from a line 90 degrees to the ground.

Trail - measured in inches - is the distance between imaginary lines drawn through the steering head to the ground and a line straight down from the axle.

Trail is what gives us the handling characteristics of our motorcycle. The more trail we have, the better our bike handles in a straight line. However, the sacrifice is lowspeed turning ability (heavy steering). As we decrease trail, we get better responsive low-speed handling (light steering) at the expense of less high-speed response.

Rake and trail on a stock production motorcycle is predetermined by the manufacturer. The builder's dimensions are based on the purpose of the motorcycle, the center of gravity of the motorcycle, and also the power-toweight ratio of the motorcycle. Take a modern sport bike for example, and compare it to a late model cruiser. These two motorcycles will be engineered for totally different purposes and will have completely different rake and trail characteristics.

Now that we realize the manufactures of our fine motorcycles know what they're doing in their engineering department, let's looks at other measurements of our motorcycle. There are several different measurements that come into play when considering frame geometry and also trail. The below diagram explains most of those dimensions.
Triple Tree Rake (B) - Triple trees can be raked or offset to add additional rake to a frame.

Neck Height (H) - This is determined by the ground clearance set by the manufacturer or by the frame design.

Trail (T) - Measured in inches, it is the distance between an imaginary line drawn through the steering head to the ground and a line straight down from the axle.

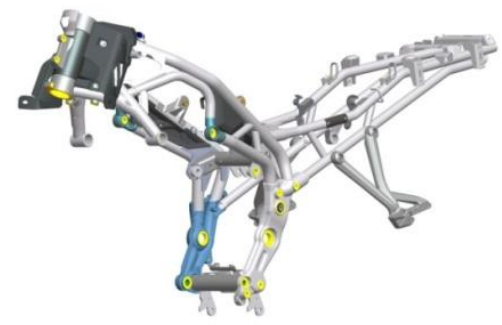

Figure 15: Frame Design

Now that we've identified some of the dimension in the front end of the motorcycle, we need to understand that modifying the motorcycle can change some of these dimensions and, in turn, modify the handling characteristics of the motorcycle. There are several ways we can modify our motorcycles and also change their handling characteristics.

When people hear the term rake," most people think of the early days of custom motorcycles. The early customs were raked" and had the front wheel several feet ahead of the frame and the term -hopper" comes into play. In the early days of custom choppers, aftermarket frames were not available, so cutting and welding the neck of the motorcycle to modify the rake was the common practice.

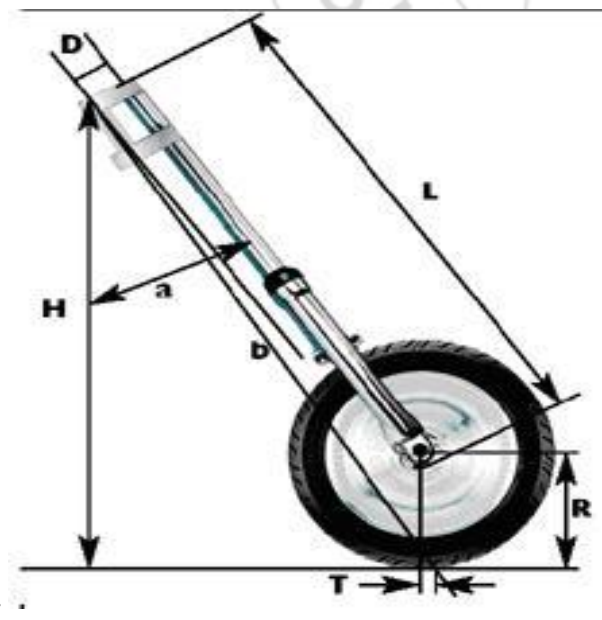

Figure 14: Frame Dimensions

Fork Length (L) - The total length of the front fork, usually measured from the top of the fork tubes to the center of the axle.

Axle Height (R) - This is the measurement from the ground to the center of the Axle

Rake Angle (A) - The angle of the steering head measured in degrees, from a line 90 degrees to the ground.

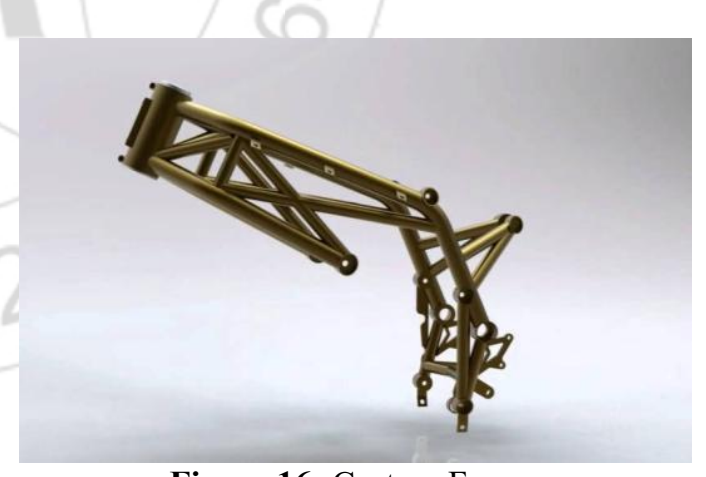

Figure 16: Custom Frame

There are other ways to modify the motorcycle and change the rake and trail. For example, lowering the motorcycle front or rear will modify the neck height of the frame, thus altering the trail of the motorcycle. Also, changing the front fork tubes or adding raked triple trees and changing the wheel sizes of the motorcycle can change the handling of the motorcycle.

\section{Step 3 - Re-Engineering}

\section{Hub Steering System}

Hub-center steering (HCS) is one of several different types of front end suspension/steering mechanisms used in motorcycles. Hub-center steering is characterized by a swing 


\section{International Journal of Science and Research (IJSR) \\ ISSN (Online): 2319-7064 \\ Index Copernicus Value (2013): 6.14 | Impact Factor (2014): 5.611}

arm that extends from the bottom of the engine/frame to the centre of the front wheel instead of a fork. The advantages of using a hub-center steering system instead of a more conventional motorcycle fork are that hub-center steering separates the steering, braking, and suspension functions.

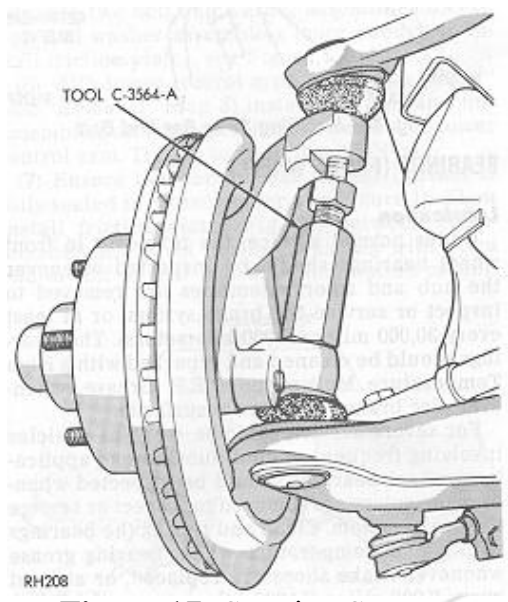

Figure 17: Steering System

With a fork the braking forces are put through the suspension, a situation that leads to the suspension being compressed, using up a large amount of suspension travel which makes dealing with bumps and other road irregularities extremely difficult. As the forks dive the steering geometry of the bike also changes making the bike more nervous, and inversely on acceleration becomes lazier. Also, having the steering working through the forks causes problems with stiction, decreasing the effectiveness of the suspension.

The length of the typical motorcycle fork means that they act as large levers about the headstock requiring the forks, the headstock, and the frame to be very robust adding to the bike's weight.

Hub-center steering systems use an arm, or arms, on bearings to allow upward wheel deflection, meaning that there is no stiction, even under braking. Braking forces can be redirected horizontally along these arms, or tie rods, away from the vertical suspension forces, and can even be put to good use to counteract weight shift. Finally, the arms typically form some form of parallelogram which maintains steering geometry over the full range of wheel travel, allowing agility and consistency of steering that forks currently cannot get close to attaining. Complex linkages tend to be involved in the steering process, and this can lead to slack, vague, or inconsistent handlebar movement across its range.

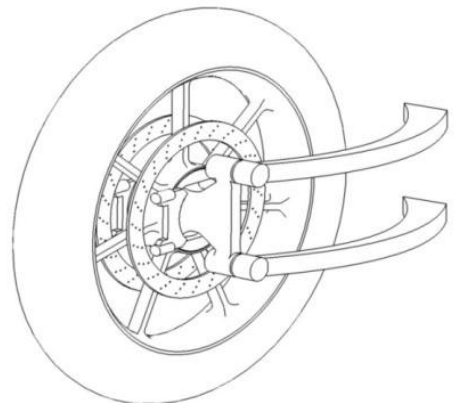

Figure 18: Hub Steering System
Hub-center steering systems have only appeared on a very few production motorcycles, and not with any great success Evolution, rather than revolution, tends to drive advancements in new models, and dictate sales. After so many years of telescopic forks, people are used to riding a bike that handles in a specific way, and almost expect the limitations, and compensation is part of the experience. Also there is a depth of knowledge known about fork based chassis design that attempts each year to get around the limitations through technological advances on the current system. Thicker and thicker fork tubes are used to reduce flex, special coatings are used to aid stiction, and greater and greater steering angles are used to counteract dive.

\section{Anti-Lock Braking System (ABS)}

An anti-lock braking system (ABS) is an automobile safety system that allows the wheels on a motorbike to maintain tractive contact with the road surface. While braking, preventing the wheels from locking up (ceasing rotation) and avoiding uncontrolled skidding. It is an automated system that uses the principles of threshold braking and cadence braking which were practiced by skillful drivers with previous generation braking systems.

ABS generally offers improved vehicle control and decreases stopping distances on dry and slippery surfaces. However, on loose gravel or snow-covered surfaces, ABS can significantly increase braking distance, although still improving vehicle control.

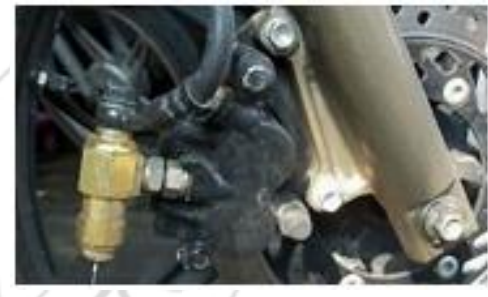

Figure 19

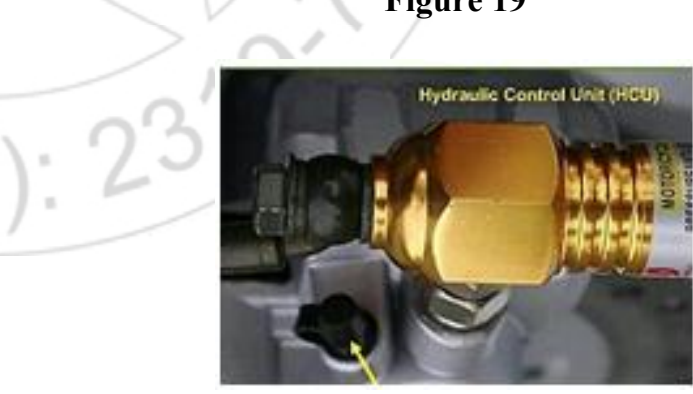

Figure 20

\section{Conclusion}

This project conclude that a custom motorcycle concept build is a complete one of the innovative and require countless hours poured into each build regardless of the style and base motorbike. We have found that it is important that each and every build that leaves the project works of assembly is a true old empire motorbike and this is why we took so much time considering each build and whether they are suitable to be part of this very special breed of motorbike. 


\section{References}

[1] The history of Motorcycle. London: Orbis Publishing in 1979 by Ayton, Cyril, Bob Holliday

[2] Lear, George and Lynn S. Mosher, Motorcycle Mechanics. Englewood Cliffs, NJ: Prentice Hall, 1997Kristin Palm

[3] Cocco G.; Motorcycle Design and Technology, 1999, Italy

[4] Test Run Of Custom Bike, By Noah Joseph, www.autoblog.com

[5] Chopper City Street Legal Bike, By Loz Blain, www.gigmag.com

[6] The Rotating Wheel Mechanism Of The Custom Bike, By BETSY MEGAS, www.quora.com

[7] Vietnamese Rider Creates His Own Custom Bike, By Damon Lowney

[8] Research \& Development On Custom Frame, Static Moto Designs 2011, www.staticmoto.com

[9] www.wikipedia.org

\section{Author Profile}

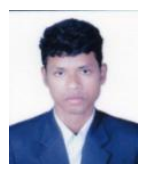

Amit Kumar Ekka is appearing for B.E degree in Mechanical Engineering from Mats School of Engineering (Mats University) in 2012 and 2016, respectively. During 2012-2016 he stayed in Automobile Laboratory, to study about IC engine.

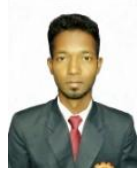

Arunesh Kujur is appearing for B.E degree in Mechanical Engineering from Mats School of Engineering (Mats University) in 2012 and 2016, respectively. During 2012-2016 he stayed in Automobile Laboratory, to study about IC engine.

Akash Bhagat is appearing for B.E degree in Mechanical Engineering from Mats School of Engineering (Mats University) in 2012 and 2016, respectively. During 2012-2016 he stayed in Automobile Laboratory, to study about IC engine.

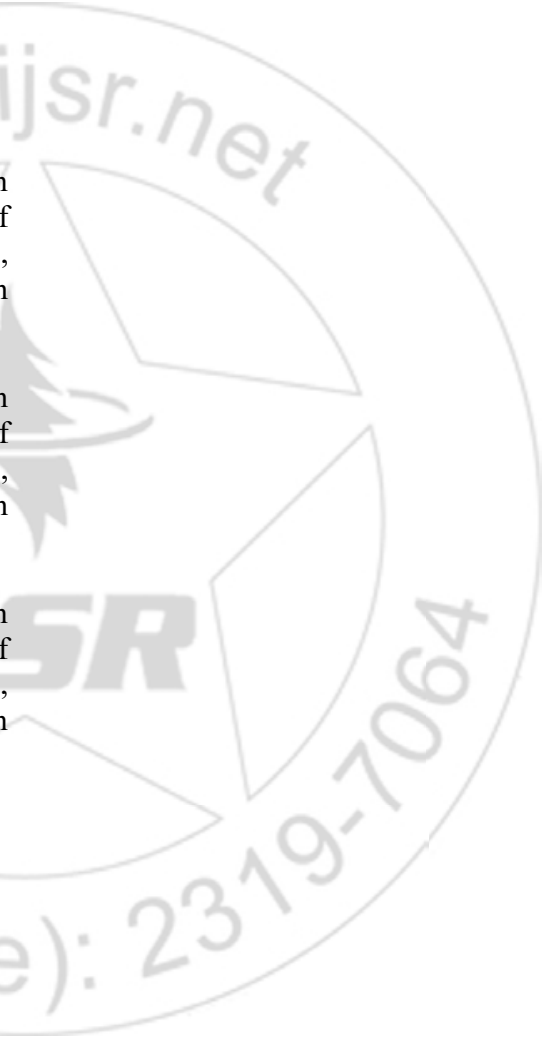

